\title{
Strategies to Increase the Number of Kenyan Diaspora in Southeast Asian Countries under the Accreditation of Kenya Mission in Bangkok
}

\author{
Peter Owiti Opiyo, Darmp Sukontasap, Jiraroj Mamadkul, Raymond Udoffe Brown \\ Institute of Diplomacy and International Studies, Rangsit University, Bangkok, Thailand \\ Email:peteowiti@yahoo.com
}

Received 2 February 2016; accepted 5 April 2016; published 8 April 2016

Copyright (C) 2016 by authors and Scientific Research Publishing Inc.

This work is licensed under the Creative Commons Attribution International License (CC BY). http://creativecommons.org/licenses/by/4.0/

c) (i) Open Access

\section{Abstract}

The enormous contribution of Kenyan Diaspora to Kenya's economy is increasingly becoming a major area of attention to policy makers. The Diaspora contributes a significant percentage to the GDP from the financial remittances they send back home. They have also been instrumental in the promotion of trade, investment, tourism, education, employment and transfer of technology and expertise to Kenya. Over $\mathbf{7 5 \%}$ of the Diaspora contribution comes from North America and Europe, leaving only $25 \%$ for the rest of the world. About $30 \%$ of Kenyan Diaspora lives in North America, 26\% in Europe, $24 \%$ in Africa, $9 \%$ in Asia while $11 \%$ is unaccounted for in different parts of the world. Approximately $0.02 \%$ of Kenyans abroad lives in Southeast Asian (SEA) countries under the accreditation of the Kenya Mission in Bangkok, namely: Thailand, Vietnam, Cambodia, Laos and Myanmar. The contribution of Kenyan residents in the five SEA countries is minimal. In this research, factors which contributed to the low number of Kenyan Diaspora in the five SEA countries, and ways in which the number could be expanded were examined. Over $70 \%$ of respondents agreed that the British colonialism and colonial legacies in Kenya, long duration of weak economies of SEA, government policies and limited diplomacy, limited information on opportunities, tough immigration policies and visa conditions, and inadequate transport system are some of the factors for the low numbers of Kenyans in SEA countries. Relaxation of tough immigration policies and rigid visa conditions, improvement on transport system, establishment of more diplomatic Missions, signing of MoUs and agreements, and information dissemination on opportunities in the five SEA countries are some of the ways to increase the numbers of Kenyan Diaspora in these countries. The research findings will help Kenya Government to formulate effective Diaspora Policy. 
Keywords

\section{Kenyan Diaspora, Southeast Asian Countries}

\section{Introduction}

The number of Kenyan Diaspora is important in Kenya's foreign policy focus because the Diaspora largely contributes to the economy of Kenya besides creating the anchor around which the sustainability of foreign relations is built. Kenyan Diaspora contributes a significant percentage to the Gross Domestic Product (GDP) from the dollar remittances they send back home. In 2014, the remittance was USD 129.1 million, accounting for nearly $11 \%$ of the government total annual revenue collection (Central Bank of Kenya, 2014). Kenyans in the United States and Europe contribute substantially to Kenya's economy compared to those living in SEA countries (World Bank, 2012; Central Bank of Kenya, 2014). In a survey conducted by the Central Bank in 2015, the remittance inflows from North America and Europe were 48.2 and 29.1\% respectively, while Africa, Asia and the rest of the world combined gave or shared the remaining 22.7\% (Central Bank of Kenya, 2015). The Diaspora is also instrumental in the transfer of technology and expertise, marketing Kenya for tourism, trade and investment. They invest in Kenya in various sectors of the economy such as land and housing, agriculture, education, energy, transport, healthcare, treasury bonds and numerous NGOs operating in the country (Lahneman, 2005; Ali, 2011; Lippoldt, 2012; KenInvest, 2014, Kenyan Diaspora Policy, 2014).

Kenya's population at home is 46,445,079 (World Population Review, 2016) while the county's Diaspora population is estimated at three million, unevenly spread all over the globe (Kenyan Diaspora Policy, 2014). The majority of Kenyans living abroad are in the United States, Europe and Africa (MFA, 2014). The number of Kenyans in the five Southeast Asian (SEA) countries, which are under the accreditation of the Kenya Mission in Bangkok, is considered very low compared to the number of Kenyans in other countries. Kenya Diaspora database at the Embassy of the Republic of Kenya in Bangkok shows that there are only 400 Kenyans in the Kingdom of Thailand, 15 in Vietnam, 10 in Cambodia, and 10 in Laos and seven in Myanmar (Sylwester, 2005; Ratha et al., 2008; MFA, 2014). In 2006, Kenya opened its foreign Mission in Bangkok to cater for its foreign relations in South East Asia, but the number of Kenyans living in these regions has remained relatively low. Therefore, this study investigated why the number of Kenyan Diaspora in the five SEA countries is so low and strategic ways through which their number can be increased.

\section{Methodology}

The Setting: This study was conducted in Kenya as well as in the five Southeast Asian countries, namely the Kingdom of Thailand, Socialist Republic of Vietnam, Kingdom of Cambodia, Lao People’s Democratic Republic (Laos PDR) and Republic of the Union of Myanmar. The study mainly targeted Kenyan Diaspora living in these five countries. It also targeted Kenyans who were working with the Ministry of Foreign Affairs of the Republic of Kenya as well as the Thai people who were working with the Ministry of Foreign Affairs of the Kingdom of Thailand. There are approximately 400 Kenyan residents in Thailand; 15 in Vietnam; 10 in Cambodia; 10 in Laos and seven in Myanmar (MFA, 2014).

Methods of Data Collection: This study mainly adopted a qualitative research design, supported by empirical data from both primary and secondary sources. Key informant interviews, focus group discussion, observation and documentary analysis were used as methods of data collection. The government documents analyzed include the Kenyan Diaspora Database, Kenya Vision 2030, The Second Medium Term Plan (MTP) 2013-2017 and Ministry of Foreign Affairs policy documents.

To conduct key informant interviews, well informed and experienced individuals were selected from Kenyans who had lived in host countries for at least two years and considered knowledgeable on the subject matter under study. Standardized open-ended key informant interviews had specific questions which were pre-determined and asked to all the participants the same way. However, participants were allowed to respond freely. Follow up interviews and peer reviews were used to enrich the data (Marshall \& Rossman, 2011; Rosman \& Rallis, 2012). Focus Group Discussion was conducted on respondents drawn from the Ministry of Foreign Affairs of the Kingdom of Thailand, Ministry of Foreign Affairs and International Trade of the Republic of Kenya, Kenya Di- 
aspora Association and Kenya Embassy, Bangkok.

Study Participants: Two categories of participants were used in this study. The first category consisted of government officials working in the Ministry of Foreign Affairs of the Republic of Kenya and those working in the Ministry of Foreign Affairs of the Kingdom of Thailand. There was also the staff of Kenya Embassy in Bangkok. These were mainly experts in high diplomatic positions. The participants were selected based on their varied experience in diplomatic career and their knowledge of current issues in Southeast Asia. The Second category constituted Kenyans who are living in five SEA countries. Participants selected in the study, under this category, were Kenyans who had at least two years experience in any of the five SEA countries and are above 18 years old.

Sampling and Sample Size: Purposive sampling was used in this study. For key informants, because of the valuable information they had and given their senior positions in the social, political and administrative realms, the sample size of 12 was considered adequate (Bernard \& Ryan, 2010; Marshall \& Rossman, 2011; Rosman \& Rallis, 2012). For focused groups-interviewing four groups, each comprising four individuals was adequate (Bernard \& Ryan, 2010; Boeije, 2010; Rosman \& Rallis, 2012). Therefore the total number of participants (n) was 28.

\section{Results and Discussions}

\subsection{Factors Contributing to the Low Number of Kenyans in the Five SEA Countries}

Through informant interviews, focus group discussion, observation and document analysis, a number of factors (Table 1) which contribute to the low number of Kenyan Diaspora in the five SEA countries were revealed. The information was corroborated with existing literatures, case studies and established academic theories (Cesaratto, 1999).

\subsubsection{Historical Factors and Cultural Differences}

There are historical factors which contributed to the current low number of Kenyans in the five SEA countries. Of the historical factors, $76 \%$ (21) of the participants said that Kenyans, long before they were colonized in $19^{\text {th }}$ C, did not have serious socio-political and economic interactions with the people of Thailand, Vietnam, Cambodia, Laos or Myanmar. "There were no interactions through intermarriages, trade, investment, tourism, education or even cultural practices like religion and sports”, said a discussant. Kenyans, for example, had been followers of traditional religions, and later Islam and Christianity as opposed to the people of the five SEA countries whose majority profess Buddhism. The impact of past international trade, Industrial Revolution, colonization, Cold War and decolonization shaped human relations and interactions at global level but apparently did not influence Kenyans to have structured and regular contacts with the people of SEA countries. The same $76 \%$ of the participants curiously claimed that the slaves of African origin would have, for example, introduced aspects of African culture and the presence of Africans in SEA countries, and that would have made the region attractive to other Africans in the centuries to follow. Giving examples, the participants argued that the slave trade caused migrations and subsequent formation of African Diasporas in different parts of the world, adding that the exposure of the Western World to African continent, and the early settlements of Africans in Europe and the Americas had major impact on the international relations between African and Western countries-even long after the abolition of the slave trade in $18^{\text {th }} \mathrm{C}$. Ten percent (3) of the participants disagreed, arguing that historical factors, dating as far back as $14^{\text {th }}$ century, could not have been strong enough to continue influencing the number of Kenyan Diaspora in SEA countries in the $21^{\text {st }}$ century. However, $14 \%$ (4) of the participants were undecided and didn't provide any response. Asked through the Focus Group Discussion why they were undecided, the four (4) participants argued that they were not so sure if the historical factors, some dating back to the time immemorial, could have influenced more Africans, particularly Kenyans, to the five Southeast Asian countries.

International relations is not only build by states, international organizations and NGOs but also by historical experiences of people who travel across nations and build networks as students, researchers, scholars, geographers, tourists, traders and even slaves, especially when they engage in international realm for a long period of time. For so long, there was a near lack of people who travelled from Kenya to Southeast Asian countries or vice versa.

\subsubsection{Colonialism and Colonial Legacies}

British colonialism denied Kenyans freedom to travel and engage with the people of SEA countries. The British 
Table 1. Factors for the low number of Kenyan Diaspora in five SEA countries $(n=28)$.

\begin{tabular}{|c|c|c|c|c|}
\hline \multirow{2}{*}{\multicolumn{2}{|c|}{ Factors for the low number of Kenyan Diaspora }} & \multicolumn{3}{|c|}{ Respondents response level } \\
\hline & & \multirow{2}{*}{$\begin{array}{c}\text { Agree f (\%) } \\
76 \%(21)\end{array}$} & \multirow{2}{*}{$\begin{array}{c}\text { Disagree } \mathrm{f}(\%) \\
10 \%(3)\end{array}$} & \multirow{2}{*}{$\begin{array}{c}\text { Undecided f (\%) } \\
14 \%(4)\end{array}$} \\
\hline 1 & Historical factors and cultural differences & & & \\
\hline 2 & Colonialism and colonial legacies & $75 \%(21)$ & $11 \%(3)$ & $14 \%(4)$ \\
\hline 3 & Policies of Govt. \& limited diplomacy & $85 \%(24)$ & $11 \%(3)$ & $4 \%(1)$ \\
\hline 4 & Limited pioneer diaspora families in SEA & $72 \%(20)$ & $17 \%(5)$ & $11 \%(3)$ \\
\hline 5 & Limited information on opportunities & $93 \%(26)$ & $7 \%(2)$ & $0 \%(0)$ \\
\hline 6 & Economies of Kenya and SEA countries & $89 \%(25)$ & $7 \%(2)$ & $4 \%(1)$ \\
\hline 7 & Wars and political tension during Cold War & $74 \%(21)$ & $22 \%(6)$ & $4 \%(1)$ \\
\hline 8 & Unreliable and inadequate transport system & $89 \%(25)$ & $7 \%(2)$ & $4 \%(1)$ \\
\hline 9 & Immigration policies and visa conditions & $97 \%(27)$ & $3 \%(1)$ & $0 \%(0)$ \\
\hline
\end{tabular}

colonial policy was mainly about economic gains and domination in places where there were prospects of quick economic fortunes for the colonialists themselves. Kenya was run as a state under the United Kingdom. The imperial British colonialists grabbed African fertile land and cattle, subjected Kenyans into forced labor and over taxation, and restricted their movements not only in Kenya, but also abroad (Elkins, 2005). The kipande system or the national Identity Card introduced by the colonial authority, for example, required an African to get permission in order to visit even a relative $10 \mathrm{~km}$ away. Africans were not permitted to have contacts or networks based on trade, education, religion or even intermarriages with people from other parts of the country. To an ordinary Kenyan, it was impossible to get even where to submit application forms to get visa or what was known as pass to any of the five SEA countries-given that all the five SEA countries, except Thailand, were also under colonialism and faced similar restrictions. Seventy five percent (21) of the respondents agreed that restrictions by the British colonial government denied Kenyans the freedom to engage with people from other parts of the world including SEA. Eleven percent (3) disagreed while 14\% (4) was undecided. "The colonial government controlled not only the nation but also social interactions, economic and political organizations. Building alliances with non-British allies, especially during the Cold War period (1945-1989) would be deemed a threat to the British spheres of interests in Kenya and the East African region,” said a participant who witnessed the British colonial rule in Kenya. Even after independence in 1963, neocolonialism continued and Kenya found herself in a state where she had to play the role of a key ally of the former colonial master and the Western world, particularly in the period 1963-1998. Thus, the colonial legacies tied the country to the West against the East. Only a few Kenyans were allowed to travel abroad but mainly to Europe and USA, where they were involved in business, education or employment (Mart, 2011).

The $1^{\text {st }}$ and $2^{\text {nd }}$ World Wars which had a great impact on migrations and international exposure did not have much effect on Kenya's relationship with the five SEA countries. During the two World Wars (1914-18 \& 193945), Kenyans were recruited to fight alongside the British in Southeast Asia, particularly in Burma (Myanmar). After the end of the war, those who survived did not remain in SEA countries. Instead, they returned to Kenya (Luto, 2013). In fact, it was the experience of Kenyans in the World War II, particularly in Myanmar (formerly known as Burma), that inspired them to go back and fight for the country’s independence.

\subsubsection{Policies of Governments \& Limited Diplomatic Representation}

For a long time since independence, Kenya did not encourage her citizens to look for opportunities abroad. Instead, both the first and second Independence Governments (1963-2003), discouraged Kenyans from going abroad to look for opportunities (Okoth, 2003). People were urged to either remain in Kenya or return to Kenya after completion of studies abroad, and participate in what was popularly referred to as: building the young and independent nation (Barkan, 2004). Those who worked or lived abroad were disrespected and considered lost. "Up-to 2003, working abroad was associated with being unpatriotic and brain drain. Kenyans who worked in other places, apart from the United States and European countries, were despised even much more”, said a participant. 
There was no foreign policy to facilitate bilateral and multilateral engagements between Kenya and the five SEA countries. In fact the first serious bilateral engagement, the Joint Commission for Cooperation (JCC), was inked in Nairobi in 2010, involving Kenya and Thailand, and spelling out areas of cooperation in the fields of agriculture, education, technology, health, employment and environment (Kenya Embassy, Bangkok, 2010). "The country did not have a single diplomatic Mission or even a Consulate in all the five countries until October, 2006, when Kenya Mission to the Kingdom of Thailand was established in Bangkok and given accreditation to the five SEA countries”, said a discussant from the Ministry of Foreign affairs in Nairobi. Kenya's foreign policy orientation still reflected close affinity to Britain, and her allies from the Western World.

On the other hand, the five SEA countries also appear to have ignored Kenya and the rest of Africa in their foreign policy considerations. All the five SEA countries, except Thailand, do not have any diplomatic Mission or even a Consulate in Kenya up-to-date. "In fact countries like Laos and Cambodia do not have any diplomatic Mission in the entire African continent while Myanmar has only two Missions in Cairo and Pretoria" said a discussant. Eighty five percent (24) of the respondents agreed that the policies of governments \& inadequate diplomatic representations have contributed to the low number of Kenyans in Southeast Asian countries; 11\% (3) disagreed while $4 \%$ (1) was undecided. Asked why they disagreed, the $11 \%$ of the respondents argued that the Kenya Government did not single out the five SEA countries as no go zone for Kenyans, adding that Kenya and the countries of SEA have all along enjoyed cordial and friendly relations as they have never been involved in any kind of serious dispute.

\subsubsection{Limited Pioneer Diaspora Families in SEA Countries}

A report by the Migration Policy Institute (2015) shows that a considerable number of Kenyans who obtained visa for permanent residence in United States had their relatives already living in the US. Experience shows that people tend to migrate to places where their family members, relatives, friends or acquaintances are already present and are likely to facilitate their settlement as they reach the destination countries. This resonates well with the New Economics of Migration Theory propagated by scholars like Stark \& Bloom (1985), which considers migration as a consequence of family decision. Among the Kenyan cultures, family ties largely determine mobility, sometimes much more than economic opportunities characterized by uncertainties. In SEA, the low number or even absence of Kenyans in some countries acted, and still acts, as deterrent to Kenyans who would have wished to migrate to those countries. Up-to 1990, for example, there was no single Kenyan resident in Vietnam, Cambodia and Laos (Kenya Embassy, Bangkok, 2010). Seventy two percent (20) of the participants found absence of pioneer diaspora families as the reason for the low number of Kenyans in the five SEA countries while $17 \%$ (5) disagreed and $11 \%$ (3) were undecided. Asked why they disagreed, the five participants claimed that there were many reasons which could make people to migrate to the SEA countries other than the mere decision of family members or the existence of part of family in destination countries, adding that there were no tangible evidence that the Kenyans who were already in the five countries migrated to those countries because their families in Kenya had told them to do so. The five participants further claimed that many Kenyans in the five SEA countries were neither invited nor received by part of their respective family members in the destination countries, adding that most of them had no relatives living in the SEA countries.

\subsubsection{Limited Information on Opportunities in Southeast Asia and Kenya}

What we know about different countries around the world mainly comes from the media reports: both print and electronics, which are sometimes not accurate or not necessarily intended to build foreign relations. The other popular source of information is international research reports, for instance the reports from the World Bank. Governments may also disseminate information to their citizens, about opportunities and challenges in other countries. However, the reports or information given are sometimes inaccurate. There is much about Southeast Asia which remains unknown to Kenyans. Many Kenyans have no idea about opportunities for engagements in the fields of education, environment, employment, trade, tourism, technology and health. "It is cheaper and safer to go to hospital in Thailand than in many countries in the Western World, a fact not known to the larger majority of Kenyan population" said a discussant through face to face informant interview. On the other hand, majority of the Southeast Asian population thinks of Kenya as very unsafe for trade, investment and tourism. Most of them do not seem to appreciate the potential that some Kenyans have especially as English language teachers who can be useful and affordable in schools in the five SEA countries, or as athletes who are regular winners of marathon champions and have talents which can be taped in SEA region. Ninety three percent (26) of the res- 
pondents agreed that limited information on opportunities found in Southeast Asia and opportunities found in Kenya is a factor for the low number of Kenyans in the five SEA countries, 7\% (2) of the participants disagreed while there was no participant who was undecided. Asked why they disagreed, the two participants argued that information alone would not bring Kenyans to SEA Asia as long as the numerous challenges linked to the immigration rules and tough visa conditions remain in place.

\subsubsection{Economies of Kenya and SEA Countries}

The economies of Southeast Asian countries were not in any way doing better than Kenya's economy up to early 1990s. Actually in 1990, the GDP of Kenya was USD 11 Billion, which was higher than the GDP of Vietnam, Cambodia, Myanmar or Laos. Only Thailand's economy was doing better than Kenya's economy. It means there were no prospects for getting good jobs, trade, investment or education opportunities in the five Southeast Asian countries to attract Kenyans. With only 23.45 million people in 1990 (World Population Review, 2016), jobs were readily available in Kenya, some of them having been left by the British colonialists when the country got independence in 1963 (New York Times, 1963). "When in college or university, you knew the job you were going to do, and had options to choose from. There were jobs waiting for you and you did not need to look for them”, said a discussant. There was no much stress on the available resources such as land. This explanation resonates well with the Dual Labor Market Theory advocated by scholars like Wickens and Lang (Dickens \& Lang, 1985), who claim that migrations are caused by the structure of economies of modern developed societies, which have intrinsic demand for low paying-immigrant labor. According to the theory, the more a country develops the more it attracts the immigrant labor force. As the development of SEA countries is a recent phenomenon, the region could not have, therefore, attracted more Kenyans before early 1990s. Eighty nine percent (25) of the respondents found the not-so-strong economies of SEA countries and Kenya's relatively stable economy, in the past, as part of the reasons for the low number of Kenyans in the five SEA countries while 7\% (2) disagreed and only $4 \%$ (1) was undecided.

\subsubsection{Wars and Political Tension during the Cold War}

Political conflicts and wars in Myanmar, Cambodia and Vietnam, especially the atrocious ones of between 1955 and 1985, made parts of Southeast Asia quite insecure, lawless and less attractive to foreigners including Kenyans. The same period marked the pick of the Cold War (1945-1989), the super power rivalry and negative media publicity which discouraged Kenya, a key ally of the US in Africa, from having structured engagements with SEA countries like Vietnam which professed communist ideologies and perceived to be one of the key allies of the USSR in Asia. Seventy four percent (21) of the participants agreed that the political conflicts, tensions generated by Cold War in parts of SEA and negative media publicity, discouraged public interests in Kenya from visiting some of the five SEA countries, or from considering the citizens of such countries for social interactions, economic engagements or political relations. Twenty two percent (6) of the participants did not agree, arguing that SEA country like the Kingdom of Thailand was relatively stable and, like Kenya, was a key ally of USA, yet it had not received any significant number of the Kenyan Diaspora as late as 2000. However, $4 \%$ (1) of the respondents were undecided, arguing that they were not quite sure if the past political conflicts and Cold War rivalry could have been factors strong enough to continue determining the number of Kenyans in SEA to-date. They claimed that long after the end of the Cold War (1989), or even the end of Khmer Rouge (1979) genocidal wars in Cambodia, for example, there is no evidence that the number of Kenyans is on the increase in that particular Southeast Asian country.

\subsubsection{Unreliable and Inadequate Transport System}

There has been no reliable transport and communication system between Kenya and the five SEA countries. Up-to-date, there is only Kenya Airways (KQ), which provides direct flight services between Nairobi and Bangkok, as well as between Nairobi and Hanoi. There are no direct flights from Nairobi to Phnom Penh, Naypyidaw and Vientiane, the capital cities of Cambodia, Myanmar and Laos respectively. Eighty nine percent (25) of the participants said that unreliable and inadequate transport system between Kenya and the five SEA countries partly contributes to the low number of Kenyan Diaspora in SEA, arguing that people would not like to travel to places which are so difficult to reach due to unreliable and inadequate transport system. Seven percent (2) of the participants disagreed while 4\% (1) was undecided. Asked, through the key informant interview why they disagreed, the two participants argued that people could not just travel to places because there were good 
means of transport, adding that people travel when they are going to involve in useful activities like conferences, tourism, education, workshop or business.

\subsubsection{Rigid Immigration Rules and Tough Visa Conditions in SEA Countries}

Rigid immigration rules and tough visa conditions in SEA countries make it difficult for Kenyans to get visas. To begin with, a Kenyan citizen has to travel to another continent just to submit visa application forms at the Embassy of Laos or Cambodia which are not available in the entire African continent. There is no provision for visa application online in all the five SEA countries. A Kenyan with a tourist visa can only be in these countries for three months maximum, which is not enough for one to look for a job, attend interviews, get a Non-B Visa and process work permit. At the expiry of the tourist visa, an immigrant becomes a criminal due to overstay and a target for arrest, prosecution, fine, jail, black-listing and deportation. Kenya has diplomatic representations/ Missions in Southeast Asia. The country has provisions for online visa applications, and it gives the nationals of the five SEA countries tourist visas on arrival. However, these friendly countries have not considered the need to act in the spirit of courtesy and reciprocity and accord Kenyans tourist visa exemption or visa on arrival. This is possible and doable-even in Southeast Asian context. Southeast Asian countries like Malaysia, Singapore, Hong Kong, Laos and Philippines already give Kenyans tourist visas on arrival. It means out of the five SEA countries under the accreditation of the Kenya Mission in Bangkok, only Laos accords Kenyans the tourist visas on arrival. Ninety seven percent (27) of the participants agreed that the extreme rigid immigration policies in many SEA countries make it difficult for Kenyans to get visas and visit, work or live in these countries. Only 3\% (1) of the participants disagreed while no participant was undecided. Asked why he disagreed, the participant argued that there was no direct correlation between visa and the number of Kenyan residents in SEA countries, giving example of the Laos which readily gives Kenyans visa on arrival yet the number of Kenyans there is still very minimal.

\subsection{Ways to Increase the Number of Kenyan Diaspora in Five Southeast Asian Countries}

Table 2 summarizes ways in which the Kenya Mission in Bangkok, along with other stakeholders, should act to help increase the number of Kenyan residents in the SEA countries.

\subsubsection{Relaxation of Tough Immigration Policies and Visa Rules}

Ninety six (27) of the participants agreed that immigration and visa issues offer the biggest threat to Kenyans who would wish to live, study, tour, invest, work or do any business in Thailand, Vietnam, Cambodia, Laos and Myanmar. The participants suggested immediate bilateral intervention, at the level of government to government, to address visa problems for Kenyans in the five SEA countries. The Kenya Mission in Bangkok should liaise with other stakeholders and negotiate with host governments to relax the tough immigration policies and remove rigid visa conditions on Kenyans who visit the SEA countries. Arrangement should also be made to identify where Kenyans can forward their visa applications for countries like Vietnam, Myanmar or Cambodia which do not have Embassies in Kenya and have no provision for visa on arrival for Kenyan nationals. If necessary, both

Table 2. Ways to increase the number of Kenyan residents in the five SEA countries $(n=28)$.

\begin{tabular}{|c|c|c|c|c|}
\hline & \multirow{2}{*}{ Ways to increase the number of Kenyan Diaspora } & \multicolumn{3}{|c|}{ Respondents response level } \\
\hline & & Agree f (\%) & Disagree f (\%) & Undecided f (\%) \\
\hline 1 & Relax rigid immigration policies and visa rules & $96 \%(27)$ & $4 \%(1)$ & $0 \%(0)$ \\
\hline 2 & Image building or branding of Kenya & $74 \%(21)$ & $15 \%(4)$ & $11 \%(3)$ \\
\hline 3 & Improve transport system & $89 \%(25)$ & $7 \%(2)$ & $4 \%(1)$ \\
\hline 4 & Increase missions and review foreign policy focus & $82 \%(23)$ & $11 \%(3)$ & $7 \%(2)$ \\
\hline 5 & Information dissemination to Kenyans & $79 \%(22)$ & $14 \%(4)$ & $7 \%(2)$ \\
\hline 6 & Facilitate signing of MoUs and agreements & $73 \%(20)$ & $20 \%(6)$ & $7 \%(2)$ \\
\hline 7 & Education for more Kenyan students in SEA & $75 \%(21)$ & $14 \%(4)$ & $11 \%(3)$ \\
\hline 8 & Establish effective Diaspora Association & $82 \%(23)$ & $4 \%(1)$ & $14 \%(4)$ \\
\hline
\end{tabular}


the e-visa and manual visa applications should be introduced, especially for the three countries. To make such intervention possible, the will and role of the political leadership in Kenya and host countries are essential. Only 4\% (1) disagreed, arguing that the SEA countries are unlikely to relax visa conditions to suite Kenya's demand, given that the visa conditions apply uniformly to nationals of all countries-not only Kenyans. None of the participants was undecided

The above suggestion is in line with previous reports which show how government intervention on visa related issues can lead to increase in the number of Kenyan Diaspora in some parts of the world. Between 2002 and 2012, some 20,000 Kenyans were granted permanent residency visas by the US government in response to some diplomatic initiatives from Kenya Government. Between 2012 and 2013, the US government gave 3500 visas to Kenyan students to study in US universities (East African Standard, 2003; Rosman \& Rallis, 2012). Today there are about 150,000 Kenyans living in Texas alone in the United States (Kahura, 2003), majorly as a result of the government interventions.

\subsubsection{Image Building or Branding of Kenya as a Nation}

Seventy four percent (21) of the participants agreed that aggressive image building would help the Kenyan Diaspora to be respected and enable them to access opportunities in host countries; 15\% (4) of the participants disagreed while $11 \%$ (3) was undecided. It is important for the Kenya Mission and the Diaspora Association to lead in the process of building public understanding, in foreign countries, about Kenya and Kenyan people. There is need to assure host countries that Kenyans are good people, majority of them are not involved in criminal activities. They are very talented people who win several distinguished awards globally in various fields including athletics, environment, science and arts. "If Kenyans teach English Language in Washington DC and they are paid well there, they can as well teach English Language and be paid well in SEA countries, if their image is built properly", said a discussant. Image building will make Kenyan residents popular and able to access opportunities especially in education as students or teachers, as well as in the business or employment sectors in SEA countries. They will also find it easy with the law reinforcement who will have known that they are good people.

\subsubsection{Improvement Transport System between Kenya and SEA Countries}

Noting that the unreliable transport system makes it so difficult for the majority of Kenyan population to travel to countries like Myanmar, Laos and Cambodia, 89\% (25) of the participants suggested that the Kenya Mission in Bangkok should liaise with key stakeholders, especially the major airlines and host Governments, to initiate and negotiate Bilateral Air Services Agreements (BASAs) and Code Shares (CS) in order to increase the number of direct flights operating the routes between Kenya and the five SEA countries. Transport plays a major role in facilitating interaction and exposure between two or more nations. The findings of this study suggest that improvement on transport system, particularly introduction of direct air flight services between Nairobi and Bangkok, Hanoi, Phnom Penh, Vientiane and Naypyidaw cities will be necessary in order to enhance exchange visits, socio-economic and political interactions. Seven percent (2) disagreed with the above suggestion, arguing that placing an airline on a route is normally determined by economic assessment conducted by the airline as a business entity and not the needs of Kenya Embassy or Kenyans who want to go abroad. Only 4\% (1) was undecided.

\subsubsection{Increasing Diplomatic Missions and Reviewing Foreign Policy Focus}

Eighty two per cent (23) of the participants suggested that Kenya Government should open up more diplomatic Missions or Consulates in host countries particularly in Hanoi, Vietnam and Phnom Penh, Cambodia. Diplomatic Missions play important role in facilitating socio-economic and political engagements between citizens of sending states and those of host countries. A Mission normally facilitates Diaspora to access travel documents, statutory certificates, advisory services, business transactions, education or health services and the protection of the laws in host countries. A diplomatic Mission is therefore in a strategic position to promote and protect interests of her nationals who are in accredited countries, and make host countries attractive to more Diaspora. Kenya Embassy in Bangkok, with limited number of officers, cannot effectively serve the five SEA countries. There is need to establish more diplomatic Missions in other Southeast Asian nations where Kenya has more strategic interests like Cambodia and Vietnam. Equally important, the country needs to realign its foreign policy focus to effectively expand and strengthen bilateral and multilateral relations with Southeast Asian nations. Such policy 
focus should initiate and expand cooperation in education, agriculture, trade, investment, tourism, fishing, technology and culture. There were only 25 Kenyans in the Kingdom of Thailand, for example, by December, 2005. With the establishment of Kenya Mission in Bangkok in October 2006, the number of Kenyan residents in the Kingdom began to rise steadily and is currently estimated at 650 people. In contrast, the number of Kenyans in Vietnam and Lao, which do not have Kenyan Missions, are still very low with only 15 and 10 persons respectively (MFA, 2014). Only 11\% (3) of the respondents disagreed with the idea of Kenya opening up more Missions in Southeast Asia while 7\% (2) was undecided.

\subsubsection{Information Dissemination to Kenyans on Opportunities and Challenges in SEA}

Seventy nine percent (22) of the participants suggest that the Embassy of the Republic of Kenya in Bangkok should devise mechanism for passing vital and relevant information to Kenyans, regarding the opportunities and challenges in Southeast Asia. For example, information on opportunities in areas such as trade, investment, education and employment should be shared out, even if it means that Kenyan Ambassadors or political officers go back to Kenya so often to speak about the opportunities and challenges in SEA countries. Information on the challenges involving the immigration policies, language and cultural barriers, transport system and racism in the employment sector should also be passed to Kenyans. The role of the Embassy in passing essential information is, therefore, key because there is little information in Kenyan media or government official channels about SEA countries, except when there is a major event or crisis. However, most job seekers rely on social media, some of which may be prone to scam.

Fourteen percent (4) of the participants disagreed with the proposal while 7\% (2) were undecided. "As long as the tough visa conditions remain in place in nearly all the five SEA countries, the sensitization program or the information passed by the Embassy will not help to increase the number of Kenyans in these countries. A part from the Government officials and employees of the United Nations, no one seems to be in a position to meet the tough visa requirements in these countries. Even those who have been teaching for many years in the region are currently giving up and returning to Kenya—in dozens, or are being deported" said a discussant.

\subsubsection{Facilitation of Signing of MoUs and Agreements}

Seventy three percent (20) of the respondents said that signing and operationalization of agreements/MoUs will make SEA countries attractive, improve business activities and help to increase the number of Kenyans in the region. Sustainable foreign relations are based on legal and mutual bilateral and multilateral agreements. The Embassy should, from time to time, initiate and facilitate the signing of agreements/MOUs between governments, private sector/companies, learning institutions or individual business persons in Kenya and those in the five SEA countries. Agreements signed will provide the peoples of the six friendly countries with legal frameworks for gainful engagements in trade, investment, employment, transport, technology, tourism and education. However, twenty percent (6) of the respondents disagreed with the above suggestion, while 7\% (2) was undecided. "Some SEA countries like Laos and Myanmar have small economies which will not sustain serious relations built on MoUs and therefore the impact of many of such MoUs will neither be beneficial nor attractive to Kenyan business entrepreneurs. In any case, the five countries are keener on building strong bilateral and multilateral relations with ASEAN member states”, said one of the discussants who disagreed with the idea of signing MoUs and Agreements.

\subsubsection{Education for More Kenyan Students in SEA Countries}

The impact of education on the Diaspora number has unique ingredient in Kenya's international affairs. Education partly provides a foundation for long-term international relations. The participants suggested that the Embassy should liaise with other stakeholders such as Thailand International Cooperation Agency (TICA) and individual universities to assist more Kenyans to pursue further education in SEA countries. "They should be assisted to get appropriate information, admission, scholarship and even employment in host countries upon completion of their study programs", said one discussant. Seventy five percent (21) of the participants said that Kenyan students are likely to learn and promote the culture of host countries, establish viable networks and provide motivation for more Kenyans to come to Southeast Asia. However, 14\% (4) of the participants disagreed, arguing that the students will not increase the number of Kenyan Diaspora in the five SEA countries, since they will always go back to Kenya or proceed to the more strong economies of USA and Europe after completing their studies. Eleven percent (3) of the participants was however undecided, arguing that they were not so sure if 
education could be used to boost the number of Kenyan Diaspora in SEA countries. They said that they had never known any single Kenyan who, upon the completion of studies in any of the five SEA countries, decided to remain for even over three years and become part of the Diaspora.

\subsubsection{Establishment of Effective Diaspora Association}

The research findings suggest that for the number of Kenyan Diaspora to increase, the Embassy needs to facilitate the formation of effective Kenyan Diaspora Association which will help to promote interests of Kenyan residents in the five Southeast Asian countries. While working closely with the Embassy and other stakeholders, the Diaspora Association will be in a good position to gather information about Kenyans: their number, their competencies or qualifications, what they do and how they can be assisted to find good jobs, business or education in host countries; how they can be advised to respect the laws of host countries or how they can be facilitated to invest back in Kenya. Members of the Association can facilitate those who are arriving in host countries and help them to settle as fast as possible. Suggestion on the formation of effective Diaspora Association was received from $82 \%$ (23) of the participants, while $4 \%$ (1) of the participants disagreed and $14 \%$ (4) was undecided. Asked why they thought a vibrant Diaspora Association would be a panacea to the low number of Kenyan residents in the five SEA countries, the participants argued that the Association would help to provide policy proposals to the Government of Kenya to address challenges facing the Diaspora, and in the process enhance their role in Kenya's development. Asked through the Focus Group Discussion why they were undecided, the four (4) participants argued that Diaspora Associations of some African countries operating in Thailand have been used by members to propagate the ills of African developing countries such as organized crime, corruption, tribalism, nepotism, gossip and ideas which can never be good to anybody or to any nation. The 4 participants argued that there would be no need for a Diaspora Association which would disturb and upset interest of Kenyans in Southeast Asian countries. However, the 14\% (14) of the respondents who were undecided argued they were not so sure that the Association effective enough to alleviate the challenges facing Kenyans in SEA countries such as the difficulty of transferring money to Kenya, unemployment, underemployment or racialism.

\section{Conclusion}

This study investigated why there are a few Kenyan residents in Southeast Asian countries, which are under the accreditation of the Kenya Mission in Bangkok, and ways to increase their number. Information was gathered from Kenyan Diaspora in Thailand, Cambodia, Vietnam, Laos and Myanmar and also from the Ministry of Foreign Affairs and International Trade of the Republic of Kenya and the Ministry of Foreign Affairs of the Kingdom of Thailand. According to the results obtained, relaxation of tough immigration policies and rigid visa conditions, improvement on transport system, image building (branding Kenya), establishment of more diplomatic Missions, signing of MoUs and agreements, information dissemination on opportunities in the five SEA countries and establishment of effective diaspora association, are some of the ways to increase the numbers of Kenyan Diaspora in these countries. Bureaucracy in offices, political unrest and insecurity in some countries occasionally interfered with the process of data collection but did not in any way compromise the quality of the research. Further research to find ways of increasing the Diaspora contribution to the Kenyan economy is necessary.

\section{References}

Ali, O. H. (2011). The African Diaspora in the Indian Ocean World. New York: Schomburg Center for Research in Black Culture. http://exhibitions.nypl.org/africansindianocean/index2.php

Barkan, J. D. (2004). Kenya after Moi. Foreign Affairs, 183, 9-10. http://dx.doi.org/10.2307/20033831

Bernard, H. R., \& Ryan, G. W. (2010). Analyzing Qualitative Data. Los Angeles, Thousand Oaks, CA: Sage Publications.

Boeije, H. (2010). Analysis in Qualitative Research. Los Angeles: Sage Publications

Central Bank of Kenya (2014). Diaspora Remittances.

https://www.centralbank.go.ke/images/docs/CBKAnnualReports/AR2013.pdf

Central Bank of Kenya (2015). Diaspora Remittances.

https://www.centralbank.go.ke/index.php/diaspora-remittances

Cesaratto, S. (1999). Savings and Economic Growth in Neo-Classical Theory. Cambridge Journal of Economics, 23, 777- 
793. http://dx.doi.org/10.1093/cje/23.6.771

Dickens, W. T., \& Lang, K. (1985). A Test of Dual Labor Market Theory. American Economic Review, 792-805. http://www.nber.org/papers/w1314

Elkins, C. (2005). Imperial Reckoning: The Untold Story of Britain's Gulag in Kenya. Britain: Henry Holt/Jonathan Cape.

East African Standard (2003). Why Kenya Has Biggest Foreign Student Body in U.S. http://www.allafrica.com/stories/200302170068.html

KenInvest (2014). Kenya Targets Doubling Foreign Investment in 2014. http://www.investmentkenya.com/latest-news/557-kenya-targets-doubling-foreign-investment-in-2014

Kenya Embassy, Bangkok (2010). Political Report.

Kenyan Diaspora Policy (2014). http://www.kenyaembassy.com

Lahneman, W. J. (2005). Impact of Diaspora Communities on Global and National Politics. Report on Survey of the Literature, CIA Strategic Assessment Group and University of Maryland, July.

http://commons.erau.edu/cgi/viewcontent.cgi?article=1002\&context=db-security-studies

Lippoldt, D. (2012). Policy Priorities for International Trade and Jobs. International Collaborative Initiative in Trade and Employment. OCED. http://www.oecd.org/site/tadicite

Luto, J. (2013). Fighting with the Fourteenth Army in Burma (pp. 204-218). Barnsley: Pen \& Sword Books.

Marshall, C., \& Rossman, G. B. (2011). Designing Qualitative Research (5th ed.). Thousand Oaks, CA: Sage Publications.

Mart, C. T. (2011). British Colonial Education Policy in Africa. Internal Journal of English and Literature, 2, 190-194. http://www.academicjournals.org/ijel

MFA (2014). Kenya MFA Diaspora Database, December 2014.

Migration Policy Institute (2015). RAD Diaspora Profile: The Kenyan Diaspora in United States. http://www.migrationpolicy.org/sites/default/files/publications/RAD-KenyaII.pdf

New York Times (Dec. 12, 1963). http://learning.blogs.nytimes.com/2011/12/12/dec-12-1963-kenya-gains-independence/

Okoth, K. (2003). Kenya: What Role for Diaspora in Development?

http://www.migrationpolicy.org/article/kenya-what-role-diaspora-development

Ratha, D., Mohapatra, S., \& Plaza, S. (2008). Beyond Aid: New Sources of Innovative Mechanisms for Financing Development in Sub-Saharan Africa. World Bank Policy Research Working Paper No. 4609, Washington DC: The World Bank. http://siteresources.worldbank.org/INTPROSPECTS/Resources/334934-1110315015165/wps4609_BeyondAid.pdf http://dx.doi.org/10.1596/1813-9450-4609

Rosman, G. B., \& Rallis, S. F. (2012). Learning in the Field: An Introduction to Qualitative Research. Thousand Oaks, CA: Sage Publications.

Stark, O., \& Bloom, D. (1985). The New Economics of Labor Migration. American Economic Review, 75, 173-178.

Sylwester, K. (2005). Decolonization and Economic Growth: The Case of Africa. Journal of Economic Development, 30, 87-102.

World Bank (2012). Migration and Remittances: Recent Developments and Outlook. Washington DC: World Bank. https://siteresources.worldbank.org/INTPROSPECTS/Resources/334934-1288990760745/MigrationandDevelopmentBrief 22.pdf

World Population Review (2016). Kenya Population 2015. http://worldpopulationreview.com/countries/kenya-population/ 